\title{
THE INFLUENCE OF TOOL COMPOSITE'S STRUCTURE DURING PROCESS OF DIAMOND GRINDING OF CERAMIC MATERIALS
}

\author{
Józef Gawlik ${ }^{1}$, Magdalena Niemczewska-Wójcik ${ }^{1}$, Joanna Krajewska ${ }^{1}$, Serghej V. Sokhan² \\ E.A. Paščenko ${ }^{2}$, T.S. Žuk ${ }^{3}$ \\ ${ }^{1}$ Cracow University of Technology, Institute of Production Engineering, Poland \\ ${ }^{2}$ Institute for Superhard Materials, Kiev, Ukraine \\ ${ }^{3}$ National Technical University, Kiev, Ukraine \\ Corresponding author: \\ Magdalena Niemczewska-Wójcik \\ Cracow University of Technology \\ Institute of Production Engineering \\ Al. Jana Pawla II 37, 31-864 Kraków, Poland \\ phone: $(+48) 501456836$ \\ e-mail: niemczewska@mech.pk.edu.pl
}

Received: 24 September 2014

Accepted: 10 October 2014

\begin{abstract}
This paper presents the results of the tests performed during the grinding process of the ceramic materials: - polycrystalline ceramics (Zirconium $\mathrm{ZrO}_{2}$ ) and mono-crystalline ceramics (sapphire $\alpha-\mathrm{Al}_{2} \mathrm{O}_{3}$ ) by the diamond tools. Studies have shown that the concentration (thickening) of the tool composite changes the tool's pore structure when using suitable wetted adamantine additives. Such modified composite has positive impact on tribological properties of the subsurface layer of the machined components. This is manifested by the reduction of the surface roughness and reduction of the vibration amplitude of the coefficient of friction. The possibilities of the positive effects when using wetted additives on the tool's composite during the pressing (briquetting) stage confirm the study results.
\end{abstract}

KEYWORDS

ceramic materials, modified diamond tools, surface geometric structure.

\section{Introduction - characteristics of a research problem}

The development of the electronics, electrical engineering, mechanical engineering and medical technology created an increasing demand for products made of high quality materials. The quality of those products' surface and the accuracy of manufacturing processes are the key factors to their reliable usage $[1,2]$. During the manufacturing, a machining centers of high accuracy are used due to the huge shape and size diversity of these products and relatively small series production. Those machining centers are characterized by high flexibility of the retrofitting system [3]. In order to obtain the precision in the elements made out of difficult-to-cut ceramic materials (sapphire and zirconium) grinding with diamond abrasive wheels is used [4-6] .During the precision grinding of spherical and ceramics elements with an accuracy of $\leq 1 \mu \mathrm{m}$ a problem with providing a required roughness on the spherical surface of the element in the range of $\mathrm{Ra}=0.010-0.020 \mu \mathrm{m}$ occurs. It is also crucial to use the appropriate measurement techniques to identify the geometric structure of the machined surfaces [7-9].

Selected physical and mechanical properties of the mono-crystalline ceramics (sapphire) and polycrystalline ceramics (zirconium) obtained by A.A. Galkina from Institute of Technology and Physics in Donetsk are presented in Table 1.

Table 1

Properties of materials used during precision grinding process.

\begin{tabular}{l|c|c}
\hline Parameter & Sapphire & Zirconium* \\
\hline Bending strength $[\mathrm{MPa}]$ & $>400$ & 850 \\
\hline $\begin{array}{l}\text { Critical intensity of crack for- } \\
\text { mation } \mathrm{K}_{1 C}\left[\mathrm{MPa}^{-1}\right]\end{array}$ & 3.5 & $8-11$ \\
\hline Young's modulus $[\mathrm{GPa}]$ & 400 & 209 \\
\hline Density $\left[\mathrm{g} / \mathrm{cm}^{3}\right]$ & 3.99 & 6.05 \\
\hline Micro-hardness $[\mathrm{GPa}]$ & $19.4-22$ & $10-12$ \\
\hline$*$ Ceramics' chemical composition: $\left(\mathrm{ZrO}_{2}+\mathrm{HfO}_{2}\right)-$ the \\
basic ingredient; $\mathrm{Y}_{2} \mathrm{O}_{3}-5.3 \% ; \mathrm{Al} \mathrm{O}_{3}-<0.05 \% ; \mathrm{Fe}_{2} \mathrm{O}_{3}$ \\
$-<0.01 \%$;iO $\mathrm{O}_{2}-<0.02 \% ;$ content of tetragonal phase - \\
$96 \% ;$ content of monoclinic phase $-4 \%$.
\end{tabular}


The shaping mechanism of polycrystalline and mono-crystalline ceramics' subsurface layer differs from processes that occur during the metal grinding. The main obstacle during ceramic grinding is its high toughness and fragility of machined components. During the grinding of fragile, nonmetallic materials the following phenomena may occur: elasticplastic deformation without any destruction to the consistency (decohesion); increase of the dispersion allowance during plastic deformation; fragile destruction and chipping of the particles. During machining of the ceramic materials not only intragranular deformation occurs but also intergranular deformation takes place. This intergranular deformation is accompanied by a slip process with the rotation of grains; fragmentation of grains into separate groups (blocks) and separation of the grain boundary and of their groups. The probability of occurrence of specified decohesion mechanism is determined by the physical and mechanical properties of the materials and by the pressure on grains exerted by the treatment conditions. The occurrence of side breaches and chipping off the clusters or chipping off the groups of grains from the machined surface are the characteristic effect of the demolition of material consistency during the grinding. These processes have a huge impact on the formation of the subsurface layers' roughness.

The appearance of the formed surface of micro hollows depends on: the geometry and kinematics movement of the working part of the tool (mainly grain's geometry and distribution of their height); tools vibration towards working surface (stiffness of the machining system); elastic-plastic deformation and fragile cracking in the contact zone between the tool and the workpiece; and waviness and roughness of the working surface of the tool. The surface of the abrasive wheel has a random nature of micro-irregularity which affects the machined surface roughness. The elastic and contact displacement of individual grains in the grinding wheel affects the component roughness profile. During grinding this component does not exceed value of $2 \cdot 10^{-3} \mu \mathrm{m}$, which is why it's usually ignored [10]. The microirregularities surface of the grains (which determine their cutting ability) do not have an impact on the roughness formation [11]. Treatment conditions and physical-mechanical properties of the machined surface affects differently on the roughness formation.

The main influence on the destruction of fragile, nonmetallic consistency of the material has a value component of the normal force on diamond grain. It is necessary by the normal force to obtain its critical value. To form the side breaches. When this value is obtained by normal force, the destruction of the consistency occurs due to the process of chipping off. The value of the critical force which is necessary to create the side breaches, depends mainly on the properties of the workpiece [12].

The physical and mechanical properties of the materials (presented in Table 1) and the value of critical force in the polycrystalline ceramics (zirconium) are much larger than in the mono-crystalline ceramics (sapphire). That is why during the grinding of zirconium the critical value of shear section on grain increases, when the process of chipping off starts [4]. During the grinding of zirconium, for the chipping off process to occur, much higher cutting depth is required than during the sapphire's grinding. During the same treatment condition, the sizes of the breaches on the poly-crystalline ceramics' machined surface should be smaller.

The experimental research of ceramics samples' subsurface layer subjected to abrasive machining showed [13], that the lower the value of fragility index, the greater the depth of features in the layer. Until now the extend of influence of fragile destruction of material allowance on the formation process of micro-features inside of the subsurface layer has not been tested [11]. Presentation of the decohesion process of fragile materials (zirconium and sapphire) based on the results from the studies is impossible.

To ensure the required level of roughness of the spherical surface, a special diamond tool is used for precision and smooth grinding of ceramic materials. This diamond tool should stably maintain an interval in the cutting zone, which ensures the sufficient capacity to fit sludge. The sludge is formed during workpiece 'shredding. It is also very important to obtain the independency of the sludge flow from: time; localization; and coverage on the surface of the tool. From the prospective of the tool's material, in order to maintain listed conditions, the optimal porosity of the tool composite should be provided with low pore size distribution. Material composite designed for finishing grinding should be characterized by high dimensional stability which is appropriate for metaldiamond composites. Otherwise, the massive flow of adhesive wear products, that consists of significant amount of abrasive grains, will not allow to achieve the required, uniform product's surface roughness.

The solution to this problem is to gain the metal-diamond composite, which will have a specified amount of pores and their spatial distribution. At the beginning of thermal machining a specified concentration of the composite should be obtain. The final stage of composite sintering process ensure the formation of the phase composition and mechanical endurance. The final stage occurs without pressure. 
During formation of porous structure the main role is played by a liquid technological additive, which is used in order to moisten the powder components.

Glycerol is usually used as a wetted additive during manufacturing of the metal-diamond composites. For example, to the powder composition which consists of the: copper, lead, synthetic diamonds and hard grease a moisturizing additive is added in an amount of $2 \%$ of weight of the composite. This type of powder composition is used during the manufacturing of the tool composites, which are later used for abrasive wheels for the finish grinding of ceramic materials. At first, this kind of mixture is subjected to pre-compression at room temperature, and next to pressing process at the temperature of $553^{\circ} \mathrm{K}$. Further part of the thermal machining is at $773^{\circ} \mathrm{K}$ temperature and takes place in the pressing form without adding any additional pressure. Density measurement confirmed that sintered tool composites have relatively low amount of pores $(9.6-10 \%)$ and an open pore structure [3]. Density of the pore's size distribution can be compared to the spatial structure of the composite [10].

The researches' results are not able to compare the pores structure of metal-diamond tool composites with their usable properties which are responsible for their behavior during dynamic contact with ceramic materials during the finishing grinding. Therefore, further studies had been undertaken in order to explain the influence of pores structure of the tool composites on precision diamond grinding process of polycrystalline (zirconium $\mathrm{ZrO}_{2}$ ) and mono-crystalline (sapphire $\alpha-\mathrm{Al}_{2} \mathrm{O}_{3}$ ) ceramic materials.

\section{Research methodology}

Technology of obtaining metal-diamond tool composites out of diamond micro powder type ASM (an abrasive micro grain obtained from a synthetic diamond with and average abrasive capacity, for tools used to machining of hard materials [14]). This ASM micro powder has a granularity of $7 / 5$ and $3 / 1$ for precision grinding of ceramic materials, it requires a geometrical final formation of porous space during the thermal pressing stage.

The characteristics of nonlinearity and rheologility grow with an increase of molecular weight of homologous compounds and organic oligomers. Considering the physical and chemical properties of glycerol, it may be replaced by polyethylene glycols (PEG) which is available in form of oligomers with a different molecular weight. The research were carried out on an element of molecular weight equal to 1500 , so the molecular weight exceeds the molecular weight of glycerol which is 97 . An element PEG-1500 was modified by adding some fragments of adamantane. That helped with obtaining the substance which consists of long-chain wetted particles with heavy wetted groups on their ends (Fig. 1). Adamantane $\mathrm{C}_{10} \mathrm{H}_{16}$ is an organic chemical compound in a form of white or gray crystals, with molar mass of $136.24 \mathrm{~g} / \mathrm{mol}$ and melting temperature of $539-545^{\circ} \mathrm{K}$. This chemical compound is insoluble in water, from the chemical point of view, this is a stable compound of high symmetrical structure.

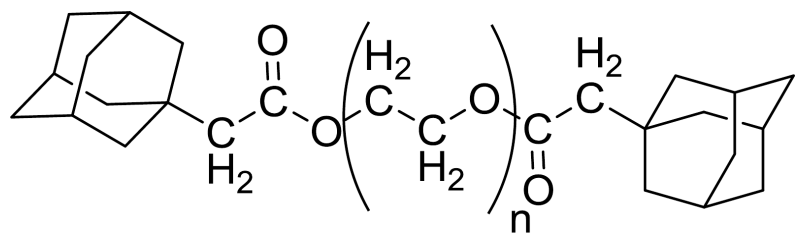

Fig. 1. A fragment of adamantane with heavy wetted groups on their ends.

A concentration of a part of the composites' samples took place when added a glycerol, while the concentration of the remaining parts occurred in connection with PEG-1500, which was modified by adamantane derivatives groups in $30 \%$ or $50 \%$. For the presented cases, the size of diamond grains was $3 / 1 \mu \mathrm{m}$.

During the first stage of an experiment, the obtained metal-diamond composites samples together with samples of sapphire and zirconium were examined for the level of wear. The research were carried out in the air on the machine II 518, at slip speed of $0.5 \mathrm{~m} / \mathrm{s}$ and under a pressure of $0.38 \mathrm{MPa}$.

During the second stage of the experiment, a ring diamond tools were used for precision diamond grinding of the spherical elements. Subsequently, those spherical elements were subjected to diamond micro powder abrasive paste during the lapping $[5$, $15,16]$.

The required shapes of the workpiece obtained through the precision positioning of the ring diamond tool to the work surface. The discrepancy of sphericity was only $1 \mu \mathrm{m}$ big and the roughness of the spherical surface was characterized by parameter $\mathrm{Ra}=0.010-0.020 \mu \mathrm{m}$.

The processes and the diamond tools for grinding of the spherical surface were developed and performed at the Institute of Super-hard Materials in Kiev thanks to the bilateral agreement between the Institute of Super-hard Materials and Institute of Production Engineering, Cracow University of Technology.

The institute of Production Engineering is equipped with a prototype and designed work- 
station for machining difficult-to-cut spherical surface as shown in Fig. 3). Very similar work-station was designed and is in use at the Institute of Superhard Materials in Kiev.

Ring diamond tools were used for preliminary grinding of the spherical surface. Those diamond tools are shown in Fig. 2 and have the following parameters: external diameter of $27 \mathrm{~mm}$ and internal of $19 \mathrm{~mm}$. The characteristics of diamond tools are as followed: diamond grains of ASO type; granularity of $125 / 100$, diamond concentration 100; metallic binder of M2-01 type. Diamond grains of ASO type consist of abrasive grains come from the synthetic diamonds, which are intended as manufacturing tools [14]. A special ring diamond tool of external diameter of $30 \mathrm{~mm}$ and internal of $20 \mathrm{~mm}$ is used during the precision grinding. The characteristics of the tool: diamond micro powder of ASM type, granularity of $7 / 5$ and $3 / 1$, diamond concentration 25 , and organic binder. An element of size of $28 \mathrm{~mm}$ should be machined with the following grinding conditions: grinding speed of 4.1-4.7 m/s; reciprocating-rotary feed of 2-3 cycle/min; in-feed of $0.015-0.2 \mathrm{~mm} /$ cycle (sapphire grinding) and in-feed of $0.015-0.2 \mathrm{~mm} /$ cycle (zirconium grinding). OAK Kool-310 type liquid is a centre of machine tools and it is used in precision, high speed centers of machine tools.

a)

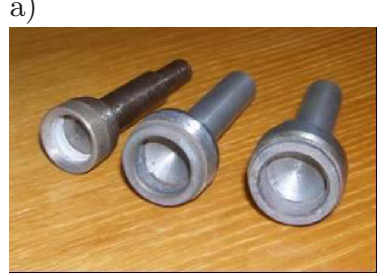

b)

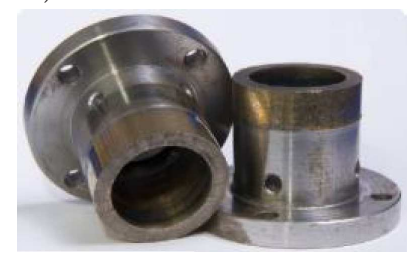

c)

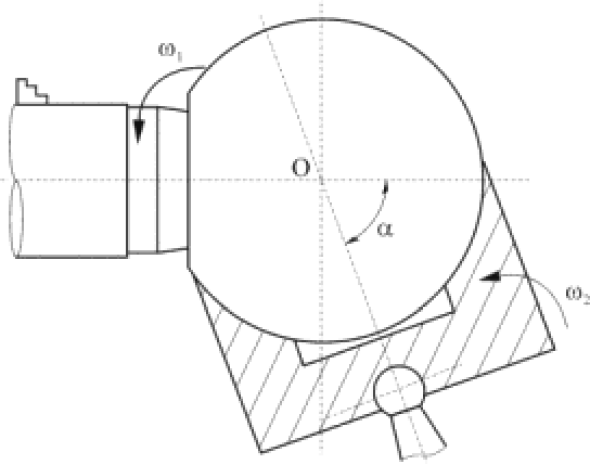

Fig. 2. The ring diamond tools used at the: a) Institute of Super-hard Materials in Kiev; b) Institute of Production Engineering, Cracow University of Technology; c) the scheme of lapping process of the spherical surface.

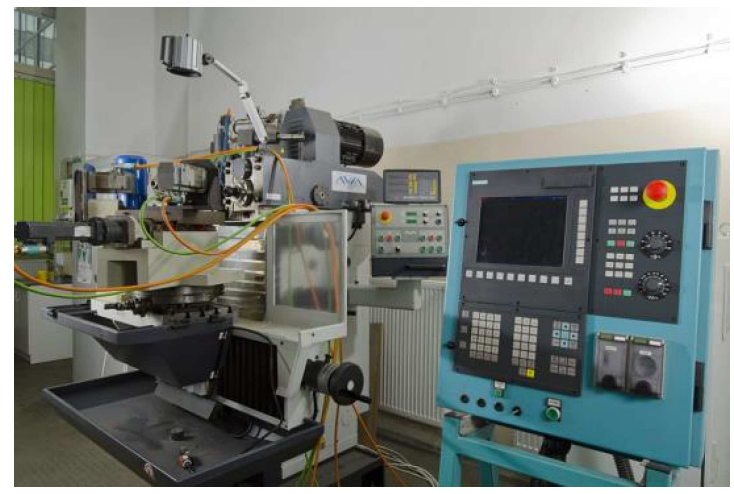

Fig. 3. Machining to create spherical elements from ceramic materials - the system was built based on the milling FNX 30P with Siemens system control [16].

During the lapping process a diamond micro powder paste was used, in order to ascertain the quality of obtained spherical surface after precision grinding, used micro powder was of a ASM type of granularity of $1 / 0$. The scheme of free lapping is shown on Fig. 2c. A spherical element with a diameter of $28 \mathrm{~mm}$ has been subjected to lapping.

The tool used during lapping is called a lapping iron with an external diameter of $27 \mathrm{~mm}$ and internal of $19 \mathrm{~mm}$. An average pressure on the working area ranges from $(3.5-3.8) 10^{2} \mathrm{kPa}$; range of changes of the lapping speed in the cutting area is at 0.18 $1.17 \mathrm{~m} / \mathrm{s}$. During the lapping process 5-10 g/min of a diamond micro powder paste was supplied.

The Institute of Super-hard Materials is equipped in an interferometer of a Linnik MII-4 type. Based on this interferometer, a non-contact interferometric 3D contour of a 'Micron-alpha' type was used in order to assess the quality of obtained spherical surface. The 'Micron-alpha contour is both an interferometer and microscope at once and, which allows to register the topographic surface in $3 \mathrm{D}$ and $2 \mathrm{D}$ profile. The results from the measurements, after the computer processing, enable the quantitative assessment of the machining surface processing using following parameters: Ra, Rp, Sm, Rmax.

\section{Research results}

In order to assess the non-linearity of viscosityliquid of glycerol which was modified by an adamantane derivatives of PED-1500, the relationship between pressure and outflow speed through the capillaries of a diameter of $0.05 \mathrm{~mm}$ was determined (Fig. 4). Figure 5 presents pore density distribution, based on their metal-diamond composites' dimensions, which were condensed by differently wetted additives. 


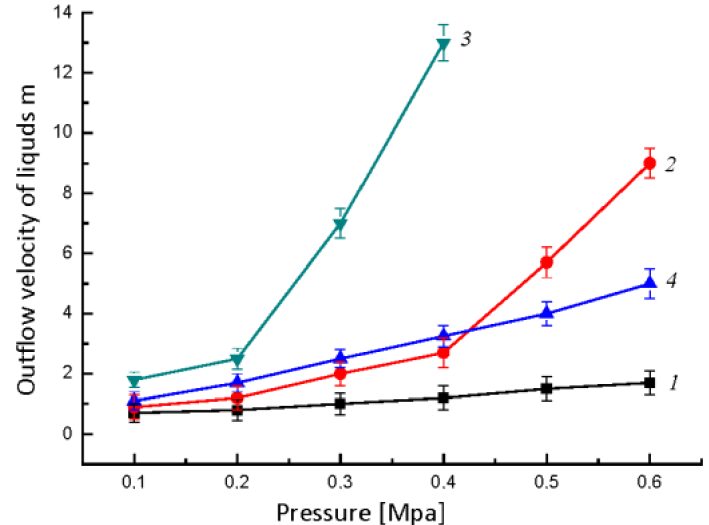

Fig. 4. Outflow velocity of wetting liquids through the capillary in dependence on the pressure: 1 - glycerol and PEG-1500; 2 with adamantane derivatives of $30 \%$; $3-$ $50 \% ; 4-80 \%$.

a)

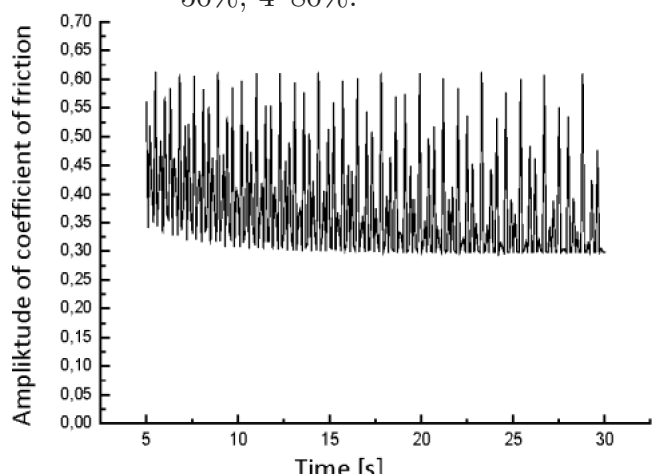

c)

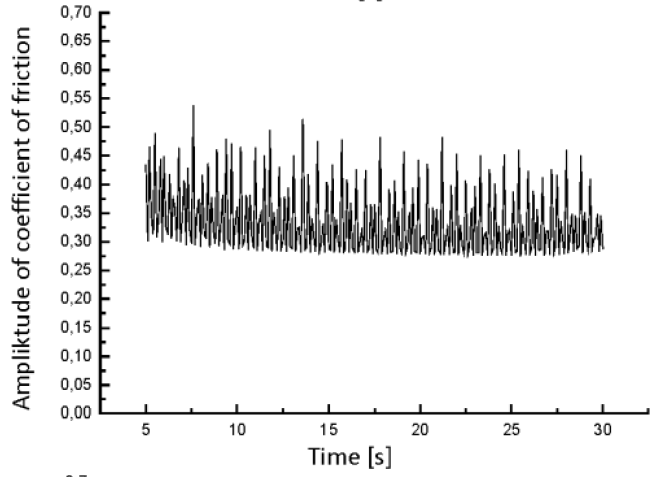

e)

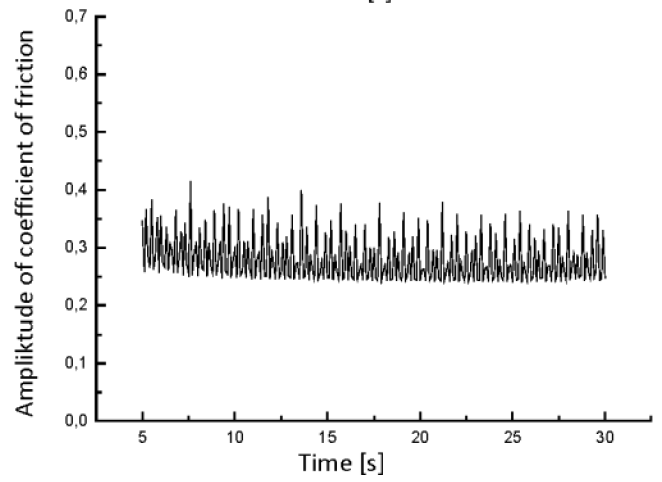

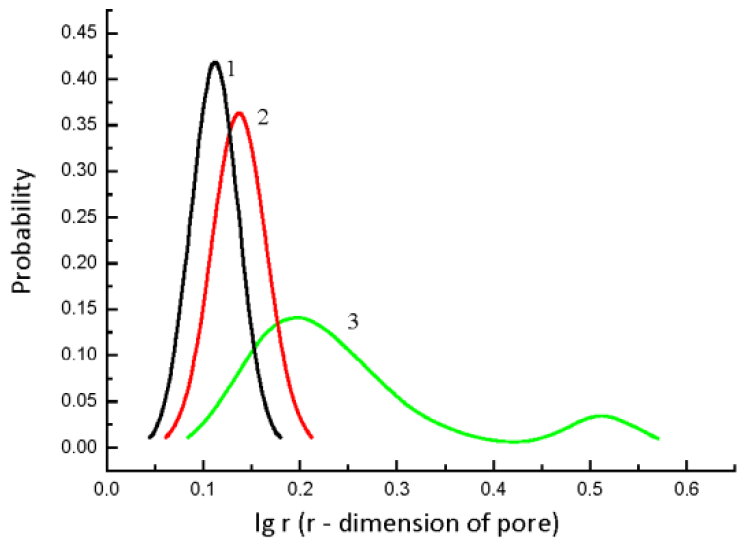

Fig. 5. Density pore distribution of metal-diamond composites with wetted additives of: $1-50 \% ; 2-30 \% ; 3-$ glycerol.

b)

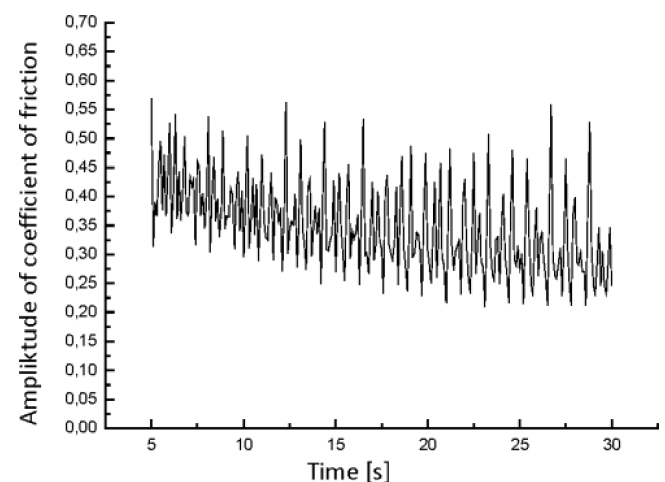

d)

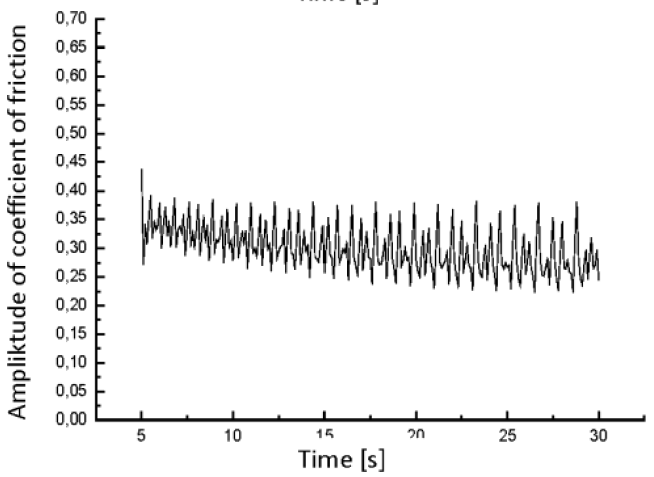

f)

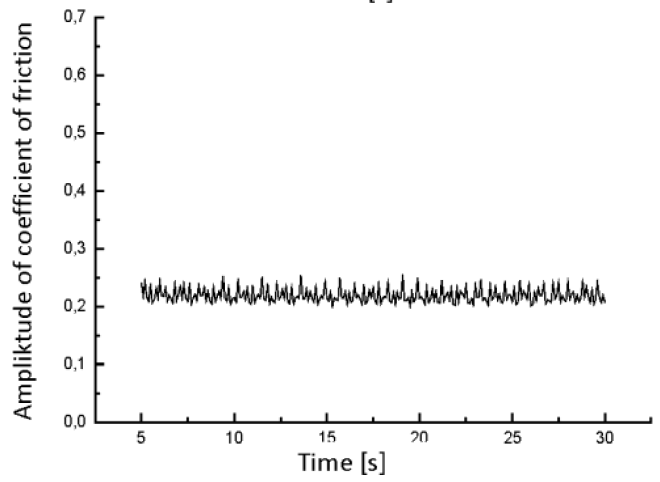

Fig. 6. The amplitude waveform of friction's coefficient during the cooperation between metal-diamond composite with sapphire and zirconium; the concentration in a glycerol environment (6a-6b); in the adamantane, finished elements PEG-1500 environment, modified in 30\% (6c-6d); and in 50\% (6e-6f). Figure 6a, 6c, 6e - sapphire; 6b, 6d, 6f zirconium. 
a)

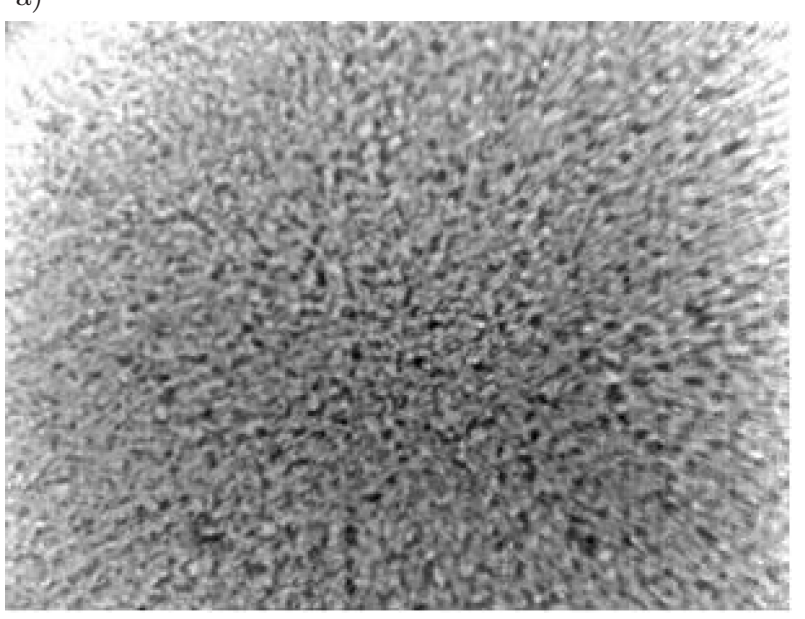

b)

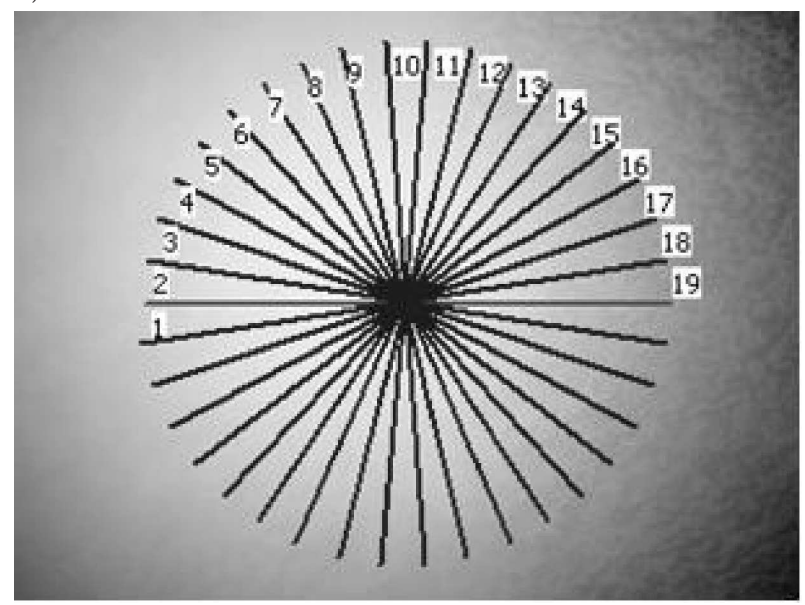

c)

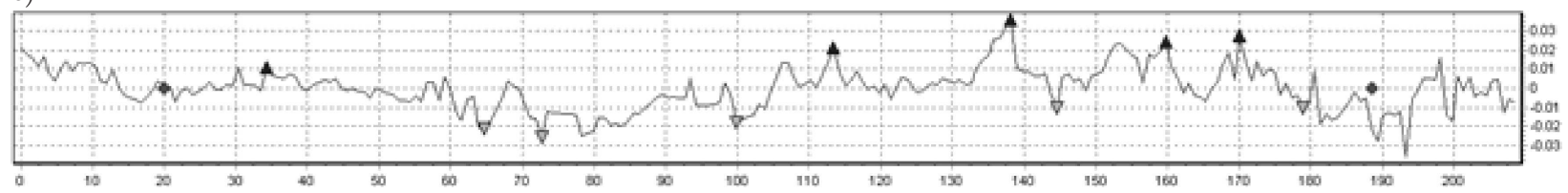

Fig. 7. Example of the obtained measurement of machines surface: a) after lapping process of ceramic with diamond micropowder abrasive paste type ASM of granularity of $1 / 0 ; \mathrm{b}$ ) a scheme of roughness measurements on spherical surface; c) a profile after shape leveling and removing. The base length of measuring section $-172 \mu \mathrm{m}$.

Figure $6 \mathrm{a}-6 \mathrm{f}$ represents the examples of the amplitude waveforms of the coefficient of friction which is characterized for the cooperation between metal-diamond composites and surfaces of the monocrystalline (sapphire) and polycrystalline (zirconium) samples.

The following roughness parameter: Rt (Total Height of roughness profile), Ra (Arithmetic Mean Deviation of the roughness profile), Rq (Root-MeanSquare Deviation of the roughness profile), $\mathrm{Rz}$ (Maximum Height of roughness profile), Rp (Maximum Peak Height of the roughness profile), Rv Maximum Valley Depth of the roughness profile), Rku (Kurtosis of the roughness profile) were determined, based on the results of the machining of the spherical ceramic surface (example Fig. 7).

\section{Discussion of the results and summary}

With condensation of the polydisperse group of different sizes and level of deformations particles, they create numerous channels with variable sections, in which local wetted additives are moving/flowing. In that case the pore spatial geometry depends on mechanism and kinematic properties of the moving organic liquid during briquetting process.
The quantitative description of this phenomenon is very complex. On the quality level, this process controls the characteristics of the liquid which can be determined as a nonlinearity of its rheological behavior.

The area of pore spatial distribution is associated with the dynamics of the moving liquid during a process of particles approaching the composite, when the wetted additives of a composite tool are a substance of high boiling temperature e.g.: glycerol (boiling temperature at $563^{\circ} \mathrm{K}$ ).

The relationship between the outflow speed of glycerol and pressure (Fig. 4) is small, it means that the non-linearity of glycerol movement is also small. When glycerol is used as a traditional wetted additive, it leads to obtaining the materials of sufficiently wide pores distribution, which has a polimodal character (Fig. 5, curve 3).

The assessment of the impact of big, un-moisten finished grains on the non-linearity of glycerol movement (Fig. 4, curves 1-4) shows that the additive of adamantane derivative in $30 \%$ increases the nonlinearity of the relationship between the flow rate and the pressure value in capillary. The maximum value of the non-linearity of the system is achieved at $50 \%$ of adamantanes' fragments. When the value is increased to up to $80 \%$, the system behaves as in the presence of glycerol. 
Obtained results correspond with the presented sizes of the pore distribution for the metal-diamond's molding forms which contain the right wetted additives (Fig. 5, curves 1-3). The maximum nonlinearity of additives' rheological behavior is obtained at narrowest pore size of the molding form distribution. Simultaneously, the regularity of the pore size inside of the fine grain of the tool's composites has a significant impact on contact behavior of the grains.

When the glycerol was used as a wetted additive during the research of abrasive wear of tool composite, relatively big changes in the amplitude of the coefficient of friction were observed. Changes were observed during the contacts with sapphire and zirconium (Fig. 6a and Fig. 6b). The results show that temporary irregularity in force distribution affects the formation of the surface defects in working material for both: sapphire and zirconium.

For both materials the amplitudes of coefficient of friction are big (Fig. 6c and Fig. 6d) when thickened composite with PEG-1500 is used and modified by $30 \%$ of adamantane derivatives.

When the modification is increased to up to $50 \%$, a significant decrease in changes in the amplitude of coefficient of friction is observed in the pair of metaldiamond composite and zirconium (Fig. 6f). It proves the strong and stable dynamic of allowence removing. The improvement of tribological properties in sapphire could not be achieved (Fig. 6e). It confirms that sapphire is a material with some anisotropy. The research showed that sapphire is more sensitive even to small heterogeneity in the pore structure of tool composites. The reduction of pore size can be achieved by using wetted additives with bigger degree of nonlinearity of their rheological properties during condensation of composites.

It is necessary to reduce the granularity to $3 / 1$ to obtain the uniform, with no visible under microscope, network of machining tracks through the right reduction ie. doubly, of the highest parameters of roughness. Additionally, when an abrasive tool with big granularity is used, the distance of profile deviation in direction to the highest tip Rp corresponds to e.g. the distance of profile deviation in direction to the highest recess $\mathrm{Rv}$. When tool with lower granularity is used, the value of $\mathrm{Rp}$ parameter reduces two to three times, and the $\mathrm{Rv}$ parameter reduces one and a half times. Therefore the influence of flat surface profile formation is confirmed. In both cases, the average value of Rku which are 3.466 and 4.370 (at its maximum value of 7.655 and 6.962 respectively) means that these values are close to their regular surface elevations distribution.

The diamond micro powder abrasive paste which is used during lapping of the ceramic surface, leaves the network of machining tracks that can be seen under the microscope but it is still less intensive than when using the granular grinding tools $7 / 5$. The quantitative assessment of high-attitude roughness parameters shows a 5-45\% increase of parameters compared to grinding with granular grinding tools $3 / 1$. It turned out that: $\mathrm{Rz}$ parameter is least sensitive; Rp parameter is most sensitive; Rv parameter is unchanged. The study shows a reverse tendency of departing from a flat surface profile during the lapping. It should be notices that the increase of a maximum value of Rku parameter (12.33) while no changes of its average value (4.965). It is probably associated with an occurrence of numerous networks of machining tracks on the machined surface.

Figure 8 a shows the polycrystalline ceramic surface after the precision grinding with granular grinding tools $3 / 1$. The results of visual assessment of mono crystalline ceramic surface indicates the presence of numerous irregular breaches, of depth equal $0.3 \mu \mathrm{m}$, distributed on surface (Fig. 8b). The breaches presence is associated with an increase of the amplitude parameters: Rz, Ra, Rq, Rt of 4-6 times, and double growth of $\mathrm{Rku}$ parameter (the maximum value being 20.72) in comparison to the values after the precision grinding of polycrystalline ceramic. For the area with lower number of breaches, the average value of $\mathrm{Rku}$ parameter is $\mathrm{Rku}=7.407$ (the maximum value being 16.80). It proves that there are a lot of cavities on the surface of the material.

There are machining tracks of depth of $0.05 \mu \mathrm{m}$ occurring after the lapping process, which can be seen under the microscope, and a lack of scattered breaches on the surface can also be observed.

The results obtained after diamond abrasive machining show that the machinability of sapphire is worse than the machinability of zirconium. The average values of sapphires' amplitude roughness parameters after lapping are 1.5-2 times higher than values after lapping of zirconium. This can be confirmed by trybological tests of pair: sapphire - polymer, on the sapphire surface a numerous of splitted polymer particles can be seen (Fig. 9). 
a)

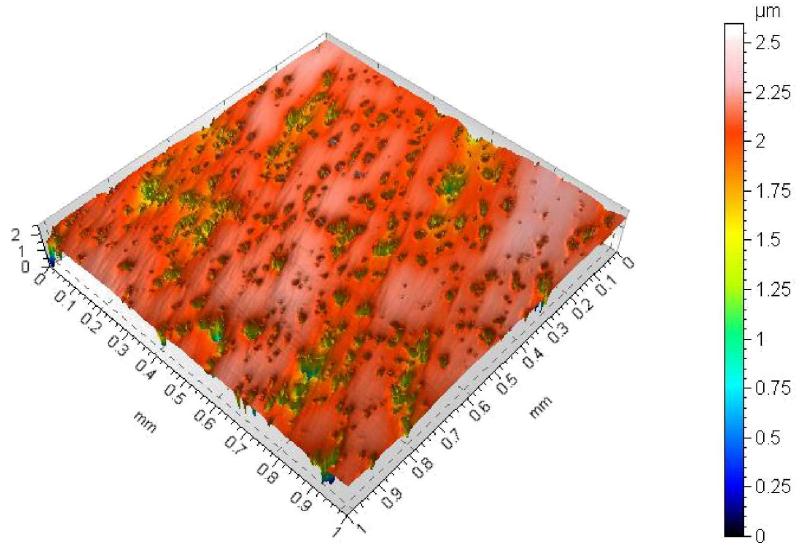

b)

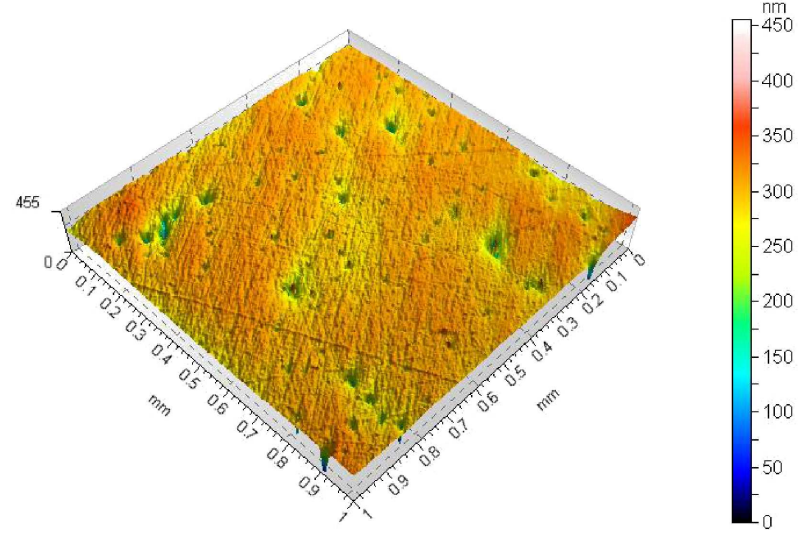

Fig. 8. The examples of surface topography after precision grinding with granular grinding tools $3 / 1$ : a) monocrystalline ceramic, b) polycrystalline ceramic.

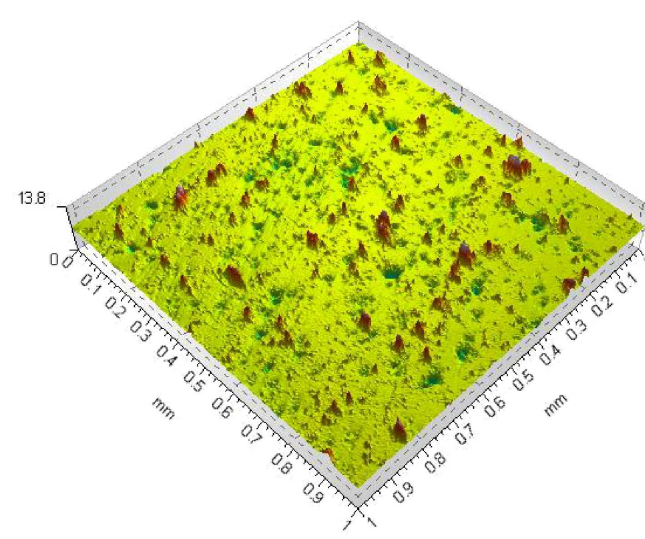

Fig. 9. The example of surface topography after tribological tests of friction knot of sapphire-polymer with visible elevation - with polymers' particles on sapphire surface [16].

To sum up the research, machining of difficult-tocut materials such as ceramic, is an important part of technological process of finished product manufacturing. The appropriate selection of: surface shaping technology and; finishing treatment parameters that ensure the optimal properties of machined surface are the key factors of: surface functionality and durability of technical systems.

\section{References}

[1] Rozenberg O.A., Voznyj V., Sochan' S., Mamalis A.G., Gawlik J., Kim D., Trends in developments in the manufacturing of hip joint: an overview, Int. J. Adv. Manuf. Technol., 27, 537-542, 2006, DOI: 10.1007/s00170-004-2189-1.

[2] Yan J., Zhang Z., Kuriyagawa T., Gonda H., Fabricating micro-structured surface by using singlecrystalline diamond end mill, Int. J. Adv. Manuf. Technol., 51, 957-964, 2010, DOI 10.1007/s00170010-2695-2.

[3] Flexible abrasive machining in medical technology. Machining of metals and construction of machine tools [in Russian], 10, 30-32, 2011.

[4] Arlamackij A.L., Abrasive machining of optical parts. Published by Mašinostroenie [in Russian], Leningrad, pp. 232, 1978.

[5] Endoprosthesis of the hip: materials and technologies [in Russian]. Edited by a member of the National Academy of Science of Ukraine N.V. Novikova and by O.A. Rozenberga and J. Gawlik, Published by: Institute for Superhard Materials of the National Academy of Science of Ukraine, ISBN 978966-2316-53-7, Kiev 2011, pp. 527.

[6] Gawlik J., Krajewska J., Niemczewska-Wojcik M., Precision Machining of Ceramic Parts, Advances in Manufacturing Sciences and Technology, 37, 4, 1930, 2013.

[7] Niemczewska-Wojcik M., Gawlik J., Sładek J., The measurement and analysis of surface geometric structure of ceramic femoral heads - SCANNING, 36, 1, 105-114, 2014, DOI 10.1002/sca.21106, Chichester, United Kingdom.

[8] Niemczewska-Wójcik M., The microscopic analysis of material's surfaces for use in medicine, Tribology - Friction, Wear, Lubrication, 3, 205-213, 2008.

[9] Niemczewska-Wojcik M., Mathia Thomas, Wójcik A., Measurement Techniques Used for Analysis of the Geometric Structure of Machined Surfaces, Management and Production Engineering Review, 5, 2, 27-32, 2014.

[10] Suslov A.G., Gorlenko O.A., Experimental and statistical methods of assurance of the surface quali- 
ty of the machine part [in Russian], Published by Mašinostroenie, pp. 303, 2003.

[11] Gusev V.V., Kalafatova L.P., Technological assurance of machining quality of the technological ceramic's parts [in Russian], Published by Donieck: GVUZ DonNTU, pp. 250, 2012.

[12] Morozov E.M, Zernin M.V, The task of the mechanics of destruction [in Russian], Published by Mašinostroenie, pp. 544, 1999.

[13] Gusev V.V., Assurance of operating characteristics of the subsurface layers of the structural ceramics [in Russian], Guidebook. Published by Mašinostroenie.
Magazine of "Surface Engineering" Annex, 9, 2-5, 2002.

[14] Woźniak K., Abrasive materials - production and properties, WNT, Warszawa, 1982.

[15] Sokhan S.V., Regularity of the abrasive-diamond lapping process of the spherical ceramic parts [in Russian], Superhard Materials, 3, 64-83, 2004.

[16] Technological system of innovative methods for the machining of materials with special properties. Project NR03 0031 10, sponsored by The National Centre for Research and Development. 